\title{
Diagnóstico da relação da comunidade com 0 patrimônio geológico por meio de instrumento de coleta de dados
}

Diagnosis OF THE RELATIONSHIP BETWEen A COMMUNITY AND THE GEOLOGICAL HERITAGE USING A DATA COLLECTION TOOL

\author{
Aline Rocha de Souza Ferreira de Castro ${ }^{1}$, Kátia Leite Mansur ${ }^{1}$, Ismar de Souza Carvalho ${ }^{1,}$ \\ 1- UFRJ. Museu da Geodiversidade, Instituto de Geociências e Progr. Pós-Grad. Geologia, Depto. Geologia, Universidade \\ Federal do Rio de Janeiro, UFRJ. Av. Athos da Silveira Ramos, 274, Cidade Universitária, Ilha do Fundão, 21941-916 Rio \\ de Janeiro - RJ. e-mail: aline@geologia.ufr.br.
}

\section{Manuscrito: \\ Recebido:20/02/2014 \\ Corrigido:06/06/2015 \\ Aceito: 21/07/2015}

Citation: Castro A.R.S.F., Mansur K.L., Carvalho I.S.. 2015. Diagnóstico da relação da comunidade com o patrimônio geológico por meio de instrumento de coleta de dados. Terræ Didatica, 11(3):162-172. $<$ http://www.ige.unicamp.br/terraedidatica/>.

Keywords: Questionnaire, Audience Research, Geological Heritage, Santana do Cariri, Ceará.
ABSTRACT : A close connection with society is essential to achieve recognition of geodiversity as geoheritage. This paper seeks to present how the population of the district of Santana do Cariri, Ceará, which is part of the Araripe Geopark, perceives and feels about the surrounding geodiversity. A questionnaire was prepared and the results of its application to 700 residents are presented. It was found that the population knows and enjoys the geological environment. This relationship, however, is different from the perception by the geoscientific community. Geodiversity is present in everyday chores, and is part of the local identity. It was found that the geoheritage perception of respondents was comprehensive, and that the heritage concept is strongly related to temporality and an aesthetic bias. Geodiversity is present in the social imagery of respondents, since the rocks and the fossils were considered as heritage.

\section{Introdução}

As ações relacionadas à conservação do patrimônio geológico têm aumentado no Brasil nos últimos anos por iniciativa, na maior parte das vezes, do empenho de geocientistas que se articulam para que exemplares raros da geodiversidade não se percam. Trata-se de uma luta para a conscientização do poder público e para a divulgação da importância científica desses elementos para a sociedade. No entanto, ainda são poucos os trabalhos que buscam conhecer melhor as comunidades que vivem no entorno de geossítios antes de iniciar um trabalho de geoconservação, de geoturismo, de divulgação científica ou de educação patrimonial. Por isso, algumas comunidades acabam por conviver com um patrimônio que, muitas vezes, lhes é imposto, pois elas não foram consultadas sobre o tema. Não o entendem como herança e, desta forma, não vêm motivos para conservá-lo.
Consultar as pessoas que residem próximos aos geossítios não significa que os pesquisadores busquem aprovação ou mesmo reconhecimento, mas compreender a forma como elas se relacionam com os elementos da geodiversidade sem juízo de valor, ou seja, diagnosticar a situação para poder elaborar estratégias em conjunto. As estratégias modificar-se-ão de acordo com cada situação, pois devem ser específicas para cada local, levando em consideração o contexto social, cultural e econômico.

Após a finalização do diagnóstico e realizadas as análises, podem ser elaboradas as estratégias necessárias para que as pessoas que convivem com a geodiversidade em seu cotidiano a reconheçam como patrimônio, ainda que não seja pelo seu valor científico. As estratégias podem ter o cunho de divulgação, de educação, de conservação, entre outras. É possível até mesmo concluir que as medidas de conservação existentes estão rígidas demais e 
que talvez seja necessário ser mais flexível, investindo mais em medidas de conscientização e reparação do que em punição, por exemplo.

É necessário conhecer e verificar como é a relação das pessoas com elementos da geodiversidade, pois são elas que residem nas proximidades dos afloramentos geológicos e têm contato com eles todos os dias. Essas pessoas devem ser compreendidas como potenciais parceiros na salvaguarda do patrimônio. Para auxiliar neste processo de aproximação da comunidade, propõem-se o uso de um instrumento de pesquisa que têm se mostrado eficiente na coleta de dados, o questionário.

\section{Objetivo}

A proposta deste trabalho é refletir sobre a importância de aproximação da comunidade acadêmica da sociedade pela aplicação de pesquisas de opinião. Serão discutidas as etapas de elaboração de um questionário que foi aplicado no município de Santana do Cariri, Ceará, parte do território do Geopark Araripe, de forma que
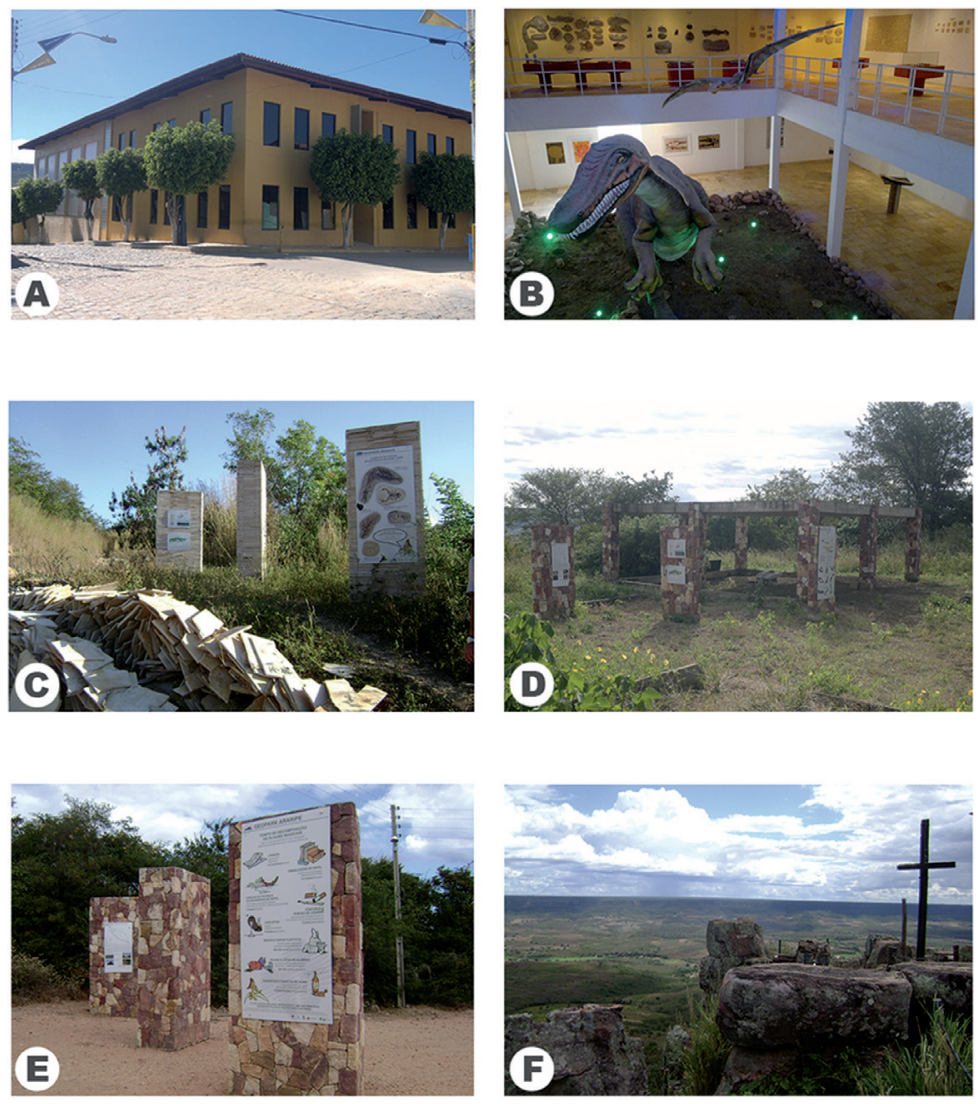

Figura 1. Geossítios do Geopark Araripe localizados no município de Santana do Cariri. (a) Fachada do Museu de Paleontologia de Santana do Cariri - MPSC; (b) Exposição de longa duração do MPSC; (c) Geossítio Pedra Cariri; (d) Geossítio Parque dos Pterossauros; (e) Musealização do geossítio Pontal da Santa Cruz e (f) Geossítio Pontal da Santa Cruz, com vista para a Chapada do Araripe. Fotos (a), (b), (d) e (f) capturadas em 2012. Fotos (c) e (e) capturadas em 2011. Fotos: Aline Castro. este instrumento seja utilizado para a elaboração de estratégias de preservação em conjunto.

\section{Caracterização da área de aplicação do questionário}

Embora os questionários sejam aplicáveis a diferentes tipos de pesquisas, deve-se ressaltar que o uso deste instrumento é ainda mais relevante em regiões onde a geodiversidade está presente e é apropriada de diferentes formas. Esse é o caso do município de Santana do Cariri, sul do estado do Ceará. O município não é relevante apenas cientificamente, mas também social e culturalmente. Ele concentra em seu território pelo menos três pontos de interesse geológicos significativos, tais como o (1) Geossítio Pontal da Santa Cruz; (2) o Geossítio Pedra Cariri e (3) o Museu de Paleontologia da Universidade Regional do Cariri, todos integrantes do Geopark Araripe, além de inúmeros locais de exploração econômica do calcário laminado e da gipsita.

A região é rica em geodiversidade e os fósseis encontrados são abundantes, muito bem preservados e diversificados, tornando-a o destino de muitos pesquisadores. Por outro lado, é também uma região economicamente restrita, que não oferece muitas oportunidades de trabalho. A situação provoca a emigração dos mais jovens, que se mudam para as capitais em busca de melhores condições de vida. Neste contexto, mesmo sendo ilegal, o comércio de fósseis pode se apresentar como uma alternativa tentadora. Além disso, a explotação do calcário e da gipsita fomenta a economia da região; portanto, trabalhar questões preservacionistas torna-se uma ação com conflitos de interesses, mas, ao mesmo tempo, necessária e, até mesmo, urgente.

Neste cenário, onde belos e raros exemplares de patrimônio geológico (com importância científica, didática, estética, econômica e cultural) se 
mesclam com uma realidade social complexa, existe uma esfera de tensão, pois são múltiplos os olhares para o mesmo patrimônio. Isso ocorre porque a relevância do patrimônio geológico não se dá somente por meio do culto à exuberância cênica e à importância científica, mas também em função das relações que as pessoas travam com ele, tanto pelo lado positivo, quanto pelo negativo. Quando a geodiversidade é qualificada como patrimônio, todas as características patrimoniais são assimiladas em conjunto. Isso implica reconhecer que o patrimônio geológico existente em Santana do Cariri, Ceará, é múltiplo, é científico, histórico, ambíguo, subjetivo, emotivo, tangível, intangível, político e dinâmico, em constante relação com os que dele se apropriam.

Com a aplicação do questionário pretende-se compreender como a população entende e se relaciona com a geodiversidade local, analisando para a comunidade geocientífica os principais pontos positivos e/ou negativos e de controvérsias teórico/ conceituais desta parcela da sociedade que tem a geodiversidade presente no seu dia-a-dia, mas que, por motivos diversos, talvez ainda não a reconheça como patrimônio.

\section{0 questionário como instrumento de pesquisa}

Há inúmeras conceituações que classificam e definem uma pesquisa de opinião de acordo com a forma com que os instrumentos de pesquisa estão articulados com as demais técnicas de coleta de dados. A metodologia escolhida na pesquisa foi a entrevista estruturada, tendo como base instrumental o questionário. Este tipo de entrevista baseia-se na utilização de um questionário como instrumento de coleta de informações, o que garante que a mesma pergunta será feita da mesma forma a todas as pessoas pesquisadas (Aguiar e Medeiros, 2009).

De acordo com Gil (1995) um questionário é

uma técnica de investigação composta por um número mais ou menos elevado de questões apresentadas por escrito às pessoas, tendo por objetivo o conhecimento de opiniões, crenças, sentimentos, interesses, expectativas, situações vivenciadas etc.

O processo de elaboração da entrevista estruturada por meio do questionário caracteriza-se por perguntas com uma ordenação, um padrão de estruturação fechado, para que não haja desvios no que se pretende identificar. As perguntas devem ser elaboradas com cautela, evitando que as indagações gerem outro tipo de interpretação diferente da proposta.

Uma entrevista estruturada baseada no questionário como instrumento de pesquisa possibilita a obtenção dados importantes, além dos que serão obtidos pelas perguntas, que são as expressões, os pensamentos e as curiosidades que só são possíveis ser captadas quando se utiliza um mecanismo de coleta que permite o contato direto com o indivíduo. Ao aplicar um questionário, o autor poderá estar emerso em outro universo não previsto, mas que poderá contribuir de forma significativa para os rumos da pesquisa. O instrumento também permite interrogar rapidamente, e com menor custo, um grande número de pessoas, e tratar os dados estatisticamente para deles tirar conclusões gerais e realizar um diagnóstico a partir dos dados obtidos (Laville \& Dionne, 1999).

\section{Metodologia geral de elaboração}

O questionário foi construído de modo que pudesse ser respondido rapidamente, por isso, houve a intenção de não elaborar questões muito grandes e complexas para o todo questionário caber em uma única página. Em experiências anteriores dos autores (Souza 2008, Vieira 2009, Teixeira et al. 2012) verificou-se que quando o questionário é muito longo, independente do número de questões, os entrevistados demonstram descontentamento ao responder as perguntas. Deve-se ressaltar que as pessoas são abordadas no contexto de seus afazeres cotidianos e não possuem qualquer comprometimento com a pesquisa. Por outro lado, não se pode simplesmente excluir questionamentos importantes devido a esta premissa, pois poucas questões podem comprometer futuras interpretações. Desta forma, buscou-se o equilíbrio na formulação das indagações, evitando questões longas e utilizando formatação concisa e objetiva.

A maior parte das perguntas foi elaborada buscando facilitar o preenchimento do questionário, por isso, optou-se por questões objetivas, ou seja, com respostas pré-determinadas. No entanto, algumas questões foram deixadas em aberto para dar espaço aos comentários não previstos, que refletem os pensamentos e as relações sociais e culturais locais. Utilizar perguntas fechadas propicia mais agilidade na sistematização dos resultados, 
porém, pode impedir o surgimento de elementos socioculturais ainda desconhecidos no momento da elaboração do questionário. De acordo com Babbie (1999) "a principal desvantagem das perguntas fechadas está na estruturação das respostas (...). A estruturação das respostas pode deixar passar algumas [informações] que são importantes".

Por isso, procurou-se manter o equilíbrio, utilizando também perguntas em aberto para que as pessoas pudessem se expressar sobre a realidade em que vivem. Deve-se ressaltar que as perguntas abertas demoram mais tempo para serem respondidas, impactando a aplicação dos questionários, e refletem o primeiro pensamento da pessoa sobre o assunto, o que veio primeiro à memória. Geralmente, as pessoas não têm tempo para elaborar a argumentação. Além disso, as questões abertas geram respostas diversas que devem ser organizadas e padronizadas, ampliando o tempo utilizado para a tabulação e para a análise.

\section{0 passo-a-passo: questões socioeconômicas}

O questionário foi elaborado em duas partes principais. A primeira parte corresponde às questões socioeconômicas. Por meio delas procura-se conhecer e caracterizar a população entrevistada por gênero, idade, escolaridade, situação econômica, religião, condição de ocupação e renda familiar.

Outras perguntas foram inseridas de acordo com as particularidades desta região. Ao perceber os problemas econômicos da região foram elaboradas questões abordando as relações das pessoas com aquele território. "Há quanto tempo você mora neste local?"; "Onde você morava antes?"; "Algum membro de sua família que morava aqui foi morar em outro estado? Quem?"; "Você já sentiu vontade de morar em outro local? Por quê??. Essas perguntas ajudaram a compreender a realidade local, como as pessoas entrevistadas se relacionam com os seus familiares e verificar a existência de emigração no município.

Para melhor caracterizar a renda familiar, duas outras questões foram acrescentadas para complementar as indagações: "Quantas pessoas moram na sua casa e quantas trabalham fora?", ajudando a conhecer ainda melhor a realidade social e econômica desta população.

\section{0 passo-a-passo: questões geopatrimoniais}

A segunda parte do questionário corresponde às questões geopatrimoniais e permeiam tematica- mente fósseis, museu, geoparque, turismo, universidade e comércio de fósseis. As perguntas "Você sabe o que é um fóssil?; "Acha que ele é importante"? permitem apenas respostas "sim" ou "não" e foram úteis para saber se o entrevistado conhece o conceito fóssil e se, de alguma forma, o considera relevante. Essas perguntas foram complementadas com outra: "E o que é?", para que o entrevistado afirmasse com as suas palavras o que é um fóssil. Desta maneira foi possível perceber se, de fato, a pessoa sabe o que é um fóssil, além de poder analisar cada conjunto de respostas, analogias culturais, percepções sobre os organismos, sobre seus vestígios e até mesmo sobre as formas de preservação.

Com a questão "Você já viu ou soube de restos de animais ou plantas nas rochas, nas pedras, ou no chão desta região"? pretendeu-se, a princípio, verificar pelo menos 3 pontos: (1) se as pessoas percebiam que ao seu redor (em toda a parte, no chão da praça, da sua casa) existem fósseis; (2) se elas percebiam que existem essas formas, mas não as associam ao termo fóssil (no caso de ter respondido sim a essa questão, mas não à questão anterior sobre fóssil) e (3) se elas compreendiam como fóssil apenas o que já foi resignificado como importante, seja por outra pessoa (algum pesquisador), ou então, por alguma instituição (museu, universidade).

"Vocêjá visitou um museu"? "Qual"? Por meio da variedade de respostas é possível saber se as pessoas da região já visitaram um museu, se elas já visitaram os museus da região e se elas já visitaram mais de um museu.

Também foram elaboradas questões que remetem ao Geopark Araripe porque nesta região existem diversos pontos de interesse geológico que fazem parte do seu roteiro (Museu de Paleontologia, Pedra Cariri e Pontal da Santa Cruz). Com a pergunta "Você já ouviu falar do Geopark Araripe"? busca-se verificar se o Geopark Araripe está difundido e apreendido pela população do município. Essa questão foi complementada com outra: "Você acha que o Geopark Araripe é importante para essa região? Por quê?" O intuito é conhecer o que a população entrevistada pensa a respeito do geoparque, apresentando a justificativa para a resposta. As justificativas são relevantes para auxiliar nas interpretações das relações locais com a geodiversidade. É possível que mesmo sem saber explicar ao certo, as pessoas possam considerá-lo importante e a pergunta seguinte "Algo mudou desde que ele foi implantado?" "Para melhor"? pode ajudar a entender melhor esse processo. 
"Existe algo importante nesta região que voce gostaria que fosse inserido roteiro do Geopark Araripe"? A última pergunta associada ao geoparque intencionou verificar se existia mais alguma coisa que fosse importante na região, mas que ainda não fazia parte do geoparque. É muito difícil aferir relevância às coisas corriqueiras que fazem parte do dia a dia, por isso, essa não é uma questão fácil de ser respondida, principalmente porque está associada ao geoparque. Por isso, em outro momento perguntou-se o que há de mais importante nesta região (município de Santana do Cariri) e, nesta ocasião, é importante deixar claro que a pergunta pode estar relacionada com qualquer coisa, em qualquer âmbito, inclusive pessoal e afetivo, mas tenha relevância para o entrevistado.

"O que falta neste município para receber os visitantes"? $O$ intuito desta questão foi verificar como os moradores da região percebem o turismo na cidade. Será que falta algo? Se falta, o que é? Essa é uma cidade turística? A cidade está preparada para atender aos turistas? Com isso, é possível tecer considerações sobre as relações sociais e políticas locais.

"Você acha que a universidade deveria se aproximar mais desta região?" Essa é uma região onde existem poucas universidades. A maioria dos estudantes universitários vai a outros municípios para poder estudar. Por isso, é necessário saber se a presença mais marcante de uma universidade é realmente almejada. Que impactos a ausência de universidades pode causar na região, em especial, para a compreensão da geodiversidade como patrimônio?

"Você já viu alguém vender um fóssil? Isso é comum?" Essa foi uma das perguntas acrescentadas após os primeiros testes de aplicação. Com ela pretendeu-se analisar se as pessoas da região sabem que vender fóssil é crime e se essa é uma ação comum na região. Também será um instrumento para saber se as políticas de conscientização estão tendo efeito e ajudar o Departamento Nacional de Produção Mineral na elaboração de novas estratégias.

A última questão é a mais complexa deste questionário porque é subjetiva e exige que seja bem compreendida. Ela consiste na leitura de palavras que podem estar associadas ao termo patrimônio, entendendo patrimônio como algo importante para a sociedade, que merece ser protegido e preservado para as futuras gerações. No momento da leitura a pessoa é convidada a dizer, em sua opinião, quais palavras apresentadas a remetiam ao conceito de patrimônio. Se a pessoa afirmar que depende da situação, a palavra deve ser marcada porque ela já associou, em alguma situação, o significado desta palavra ao patrimônio.

Dependendo da associação que se faça, todas as palavras podem ser consideradas patrimônio. Quanto mais itens são marcados, mais abrangente será a sua percepção patrimonial. As palavras selecionadas foram: casa, osso, rua, doce, montanha, pedra, praia, artesanato, arma, fóssil, comida, homem, robô, jacaré, Planeta Terra, dança, pintura de arte, prédio antigo, flor, lenda / história, árvore, caneta, site, DNA, computador, ovelha e novela. Essa é a última questão do questionário. Porém, antes de finalizá-lo definitivamente, foi realizada uma aplicação teste na região. Após esta aplicação, perguntas foram modificadas e acrescentadas, pois foi possível verificar quais questões apresentavam sentido dúbio ou eram mal interpretadas. Essa foi a fase final da elaboração do questionário antes de sua aplicação real e foi fundamental ao contribuir para o alinhamento das questões e aprimoramento com as características locais.

No presente trabalho serão avaliadas apenas as respostas referentes ao item Patrimônio.

\section{PESQUISA dE OPINIÃo COM A POPULACÃo do MUNICIPIO de SANTANA do CARIRI, CEARÁ}

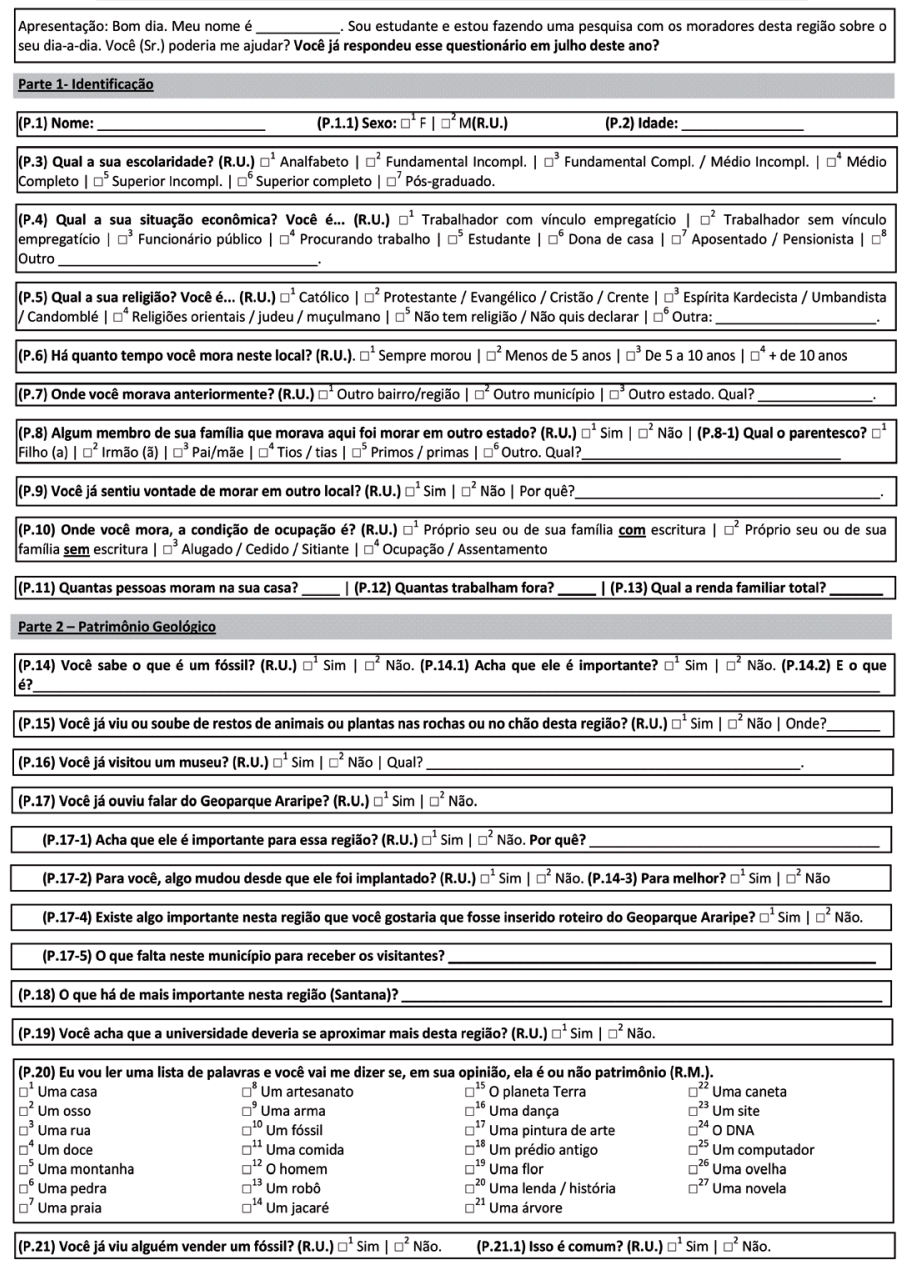

Figura 2. Questionário finalizado estruturado em uma única página. 


\section{Análise da área de estudo e planejamento de aplicação dos questionários}

O último passo antes da aplicação dos questionários foi a análise da área de estudo para verificar a melhor forma de proceder na sua distribuição pelo território municipal. Para isso, é necessário estudar a dispersão e as relações das pessoas entre os distritos municipais com os dados fornecidos pelos poderes municipal e federal.

De acordo com os dados do último Censo Demográfico realizado pelo Instituto Brasileiro de Geografia e Estatística - IBGE em 2010, o município de Santana do Cariri (sul do estado do Ceará) possui 17.170 habitantes. Esses habitantes estão distribuídos por sete distritos: Anjinhos, Araporanga, Brejo Grande, Dom Leme, Inhumas, Pontal da Santa Cruz e Santana do Cariri (que corresponde ao Centro ou à Sede do município).

A população de Santana do Cariri não está distribuída quantitativamente de forma homogênea por seus distritos e isso foi levado em consideração no planejamento da aplicação dos questionários. $\mathrm{Na}$ tabela abaixo é possível verificar como a população está distribuída pelo território municipal e constatar que a Sede do distrito se destaca pelo volume populacional em relação aos demais. Araporanga, Dom Leme e Pontal também apresentam um volume maior de habitantes, em média 3.000, e os três últimos, Anjinhos, Brejo Grande e Inhumas são os menos populosos, com cerca de $1.000 \mathrm{ou}$ menos habitantes.

Dentre as premissas adotadas para a aplicação do questionário, destaca-se que toda a população urbana municipal, com idade igual ou superior a

Tabela 1. População total residente no município e a sua distribuição pelos distritos

POPULAÇÃO MUNICIPAL

\begin{tabular}{cc|}
\hline DISTRITOS & TOTAL \\
\hline Anjinhos & 1.026 \\
Araporanga & 3.821 \\
Brejo Grande & 785 \\
Dom Leme & 2.462 \\
Inhumas & 702 \\
Pontal da Santa Cruz & 2.541 \\
Sede & 5.833 \\
TOTAL & 17.170 \\
\hline
\end{tabular}

15 anos $^{1}$ estará apta a responder o questionário. Planeja-se que sejam entrevistados 700 residentes de todos os distritos que compõem a malha urbana municipal, de acordo com o volume populacional de cada um deles. Esse número foi considerado bastante representativo para uma análise amostral de dados, abrangendo toda a malha municipal urbana e atingindo $8 \%$ da população urbana.

Buscando desenvolver uma metodologia satisfatória para a aplicação dos questionários, adequada às características populacionais do município estudado e ao porte da pesquisa que possuiu recursos, logística e objetivos diferentes daquela realizada pelo IBGE, optou-se por contemplar no estudo a população classificada pelo instituto como "Urbana".

De acordo com o IBGE², a distribuição espacial da população está relacionada à situação domiciliar, que pode ser classificada como urbana e rural. Verifica-se que as populações urbana e rural são praticamente equivalentes, onde dos 17.170 habitantes, 8.822 residem em área urbana e 8.348 em área rural. No entanto, este equilíbrio não se conserva quando o foco é a distribuição da população nos distritos, pois a distribuição da população residente nos núcleos urbanos e rurais é desproporcional. Anjinhos, Araporanga e Pontal da Santa Cruz tem a maior parte de sua população concentrada na área rural. A Sede e Inhumas são os distritos onde a maior parte da população se concentra nas áreas urbanas. A amostragem desta pesquisa se concentra na população urbana, considerando a "malha urbana" da sede municipal, localizada em Santana do Cariri e nas sedes urbanas dos distritos (núcleos ou aglomerados habitacionais).

A maior parte dos distritos deste município aproxima-se das características de área urbana isolada e de área não urbanizada, mas apresentam também características sugeridas para áreas rurais,

1 Optou-se por não entrevistar pessoas com menos de 15 anos por considerar que abaixo desta idade a pessoa não teria maturidade para responder todas as questões. Utilizou-se como parâmetro a idade estimada de término do Ensino Fundamental e ingresso no Ensino Médio e a proximidade com a idade em que é permitido o voto eleitoral, ainda que facultativo.

20 IBGE classifica o domicílio por sua situação urbana ou rural, segundo a localização apresentada. Os domicílios de situação urbana são aqueles localizados nas áreas urbanas, que são as áreas internas ao perímetro urbano de uma cidade ou vila, definido por lei municipal. As áreas urbanas são classificadas em área urbanizada, área não urbanizada e área urbana isolada. Os domicílios de situação rural são aqueles localizados nas áreas rurais, definidas como áreas externas aos perímetros urbanos, inclusive nos aglomerados rurais de extensão urbana, povoados, núcleos e outros aglomerados. Informação recebida através de mensagem eletrônica recebida pela autora em 27/12/2012, com assunto Censo Demográfico 2010 Atendimento Numero:\#68753/2012 - 1\#. 
como povoados, núcleos e aglomerados. Esses locais são distantes entre si e do Centro, não têm vias de acesso pavimentadas, saneamento básico e a maior parte da população pratica a agricultura de subsistência. Essas particularidades foram levadas em consideração no desenvolvimento do questionário e no planejamento de sua aplicação.

Além disso, deve-se considerar que os dados serão obtidos de acordo com a disponibilidade do entrevistado, as condições de acesso às residências e a dispersão da população nos distritos, privilegiando as localidades onde se encontram os núcleos habitacionais e os povoados, uma vez que o questionário é aplicado por uma única pessoa.

Por isso, para definir as condições de aplicação dos questionários buscou-se avaliar o peso demográfico de cada distrito em relação à população total do município. À cada distrito foi atribuído um peso de acordo a sua contribuição quantitativa para a população urbana total do município. Por exemplo, a população do distrito de Anjinhos possui 185 habitantes na sua zona urbana. Essa quantidade de habitantes representa $2 \%$ da população urbana total do município, que é de 8.822 habitantes. O percentual obtido foi aplicado sobre o número total de questionários, que é 700 unidades. Desta forma, em Anjinhos foram aplicados 15 questionários, pois este é o peso populacional deste distrito. Optou-se por esta metodologia visando equilibrar o peso de cada distrito e de se aproximar o máximo possível da realidade do município, numa pesquisa amostral. $\mathrm{Na}$ tabela abaixo podem ser observados todos os cálculos realizados.

Deve-se destacar que com a aplicação dos 700 questionários foi atingido $8 \%$ da população. Esse percentual é ainda mais expressivo, pois no total populacional urbano considerado no cálculo $(8.822$ habitantes) não foram extraídos os não aptos a respondê-lo. Pelos dados disponibilizados pelo IBGE, só é possível calcular a população denominada útil à pesquisa para a população total do município, conforme demonstrado na próxima tabela. Assim sendo, é possível afirmar que mais de $10 \%$ da população urbana do município de Santana do Cariri está contemplada na pesquisa.

\section{Resultados}

Alguns dos resultados socioeconômicos obtidos são apresentados na Figura 1 a seguir. Eles demonstram que a população entrevistada caracterizou-se como razoavelmente equilibrada entre os sexos e composta, em sua maior parte, por jovens e adultos entre 15 e 35 anos.

Demonstrou, também, que a questão escolar ainda é um desafio a ser enfrentado pelo município. A maior parte dos entrevistados afirmou estar cursando ou já ter concluído o Ensino Médio, mas os dados mostraram que ainda existem analfabetos na região. Esse resultado pode ser ainda mais significativo ao considerar que algumas pessoas recusaram-se a responder o questionário por julgar que não entendiam do assunto e, por isso, não foram contabilizadas nestes dados.

Além disso, não existem universidades no município. Aqueles que desejam ingressar em um curso de ensino superior têm que estudar nos municípios de Crato ou de Juazeiro do Norte, a $55 \mathrm{~km}$ e $66 \mathrm{~km}$ de distância, respectivamente. Aos poucos, com o aumento do nível de escolaridade da região, surge a oportunidade para a ampliação também do reconhecimento da importância do patrimônio geológico local.

Tabela 2. Distribuição da população municipal pelos distritos, com quantitativo de questionários aplicados. *População urbana do município, considerando os dados do Censo Demográfico de 2010. **Relevância populacional de cada distrito em relação à população total do município. Significa o quanto a população residente neste distrito é relevante quantitativamente para a população total do município.

\begin{tabular}{|c|c|c|c|}
\hline DISTRITOS & $\begin{array}{l}\text { POPULAÇÃO } \\
\text { URBANA* }\end{array}$ & $\begin{array}{c}\text { PESO } \\
\text { PERCENTUAL } \star \star\end{array}$ & $\begin{array}{l}\text { QUESTIONÁRIOS } \\
\text { APLICADOS }\end{array}$ \\
\hline Anjinhos & 185 & $2 \%$ & 15 \\
\hline Araporanga & 1148 & $13 \%$ & 91 \\
\hline Brejo Grande & 525 & $6 \%$ & 42 \\
\hline Dom Leme & 1401 & $16 \%$ & 111 \\
\hline Inhumas & 460 & $5 \%$ & 35 \\
\hline Pontal da Santa Cruz & 341 & $4 \%$ & 28 \\
\hline Sede & 4762 & $54 \%$ & 378 \\
\hline TOTAL & 8822 & $100 \%$ & 700 \\
\hline
\end{tabular}


A maior parte dos entrevistados foi composta por estudantes ou trabalhadores sem vínculo empregatício. Na realidade local, é importante considerar comum as atribuições do cotidiano, em especial, a do trabalho informal, como pedreiro ou dona de casa, que ocorrem simultaneamente com a de lavrador (um trabalho sazonal e muito comum no município) cujo ofício representa uma complementação na renda familiar, por se tratar, em sua maior parte, de agricultura de subsistência, por meio do plantio de feijão, milho, fava, entre outros.

De acordo com as entrevistas realizadas no município, a economia gira em torno da agricultura, como também dos aposentados e pensionistas. Estes últimos apareceram pouco na pesquisa, pois muitos idosos delegavam, sempre que possível, a incumbência de responder o questionário aos mais jovens. A administração municipal também é uma fonte de renda muito importante na região, onde aqueles com maior nível de estudo atuam como funcionários administrativos ou como professores.

Também merecem destaque os incentivos do governo federal, como o Programa Bolsa Família, por exemplo. Foram muitos os casos em que a renda familiar foi complementada com o respectivo benefício, como também foi a principal renda declarada por outros. Sem esses benefícios, os resultados apresentados para a renda familiar seriam ainda mais baixos ${ }^{3}$.

Por meio do referido contexto socioeconômico, foi possível compreender melhor a situação dos residentes no município, reforçando a hipótese de que a região sofre com problemas econômicos e, por causa deles, muitos entrevistados almejam ir para outros estados, a fim de fixar moradia em busca de melhores condições de vida. Talvez tal situação também interfira no modo como os habitantes

\footnotetext{
30 Programa Bolsa Família é um programa do governo federal que consiste na transferência direta de renda visando beneficiar famílias em situação de pobreza e de extrema pobreza no País. Tem como foco de atuação aqueles que possuem renda familiar per capita inferior a $\mathrm{R} \$ 70$ mensais. Os valores dos benefícios pagos variam de acordo com as características de cada família (renda mensal da família por pessoa, número de crianças e adolescentes de até 17 anos, de gestantes, nutrizes e de componentes da família). A seleção das famílias é feita com base nas informações registradas pelo município no Cadastro Único para Programas Sociais do Governo Federal. Fonte: Ministério do Desenvolvimento Social e Combate à Fome (Brasil, 2012). Disponível em: http://www.mds.gov.br/bolsafamilia. Acesso em 28 de maio de 2013.
}

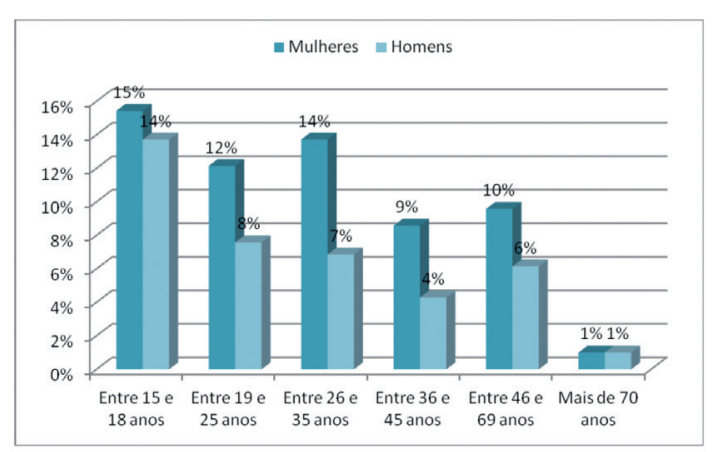

Resultado sobre Gênero e Faixa Etária

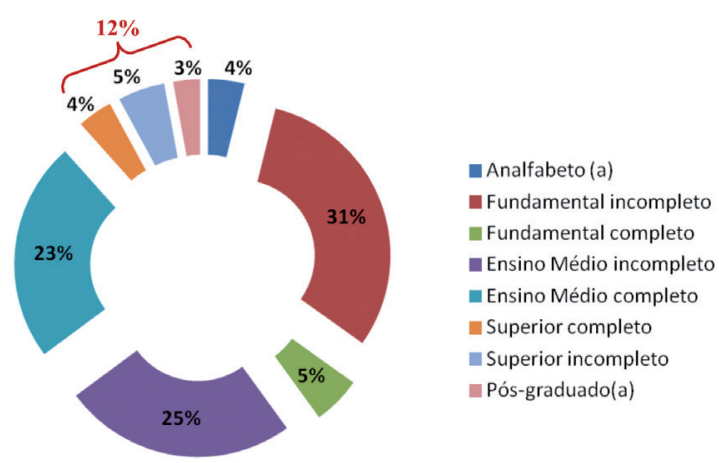

Resultado sobre Escolaridade

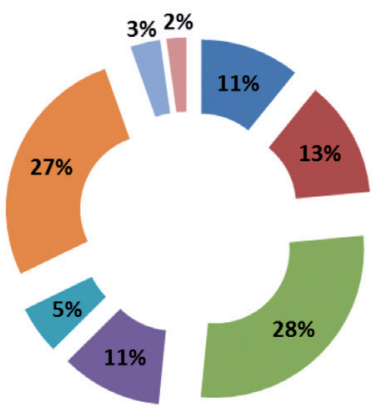

antre $R \$ 50,00$ e $R \$ 200,00$ - Entre R\$201,00 e R\$ 400,00 antre $R \$ 401,00$ e $R \$ 622,00$ antre $R \$ 623,00$ e $R \$ 800,00$ antre $\mathrm{R} \$ 801,00$ e $\mathrm{R} \$ 1.000,00$ - Entre $R \$ 1.001,00$ e $\mathrm{R} \$ 2.000,00$ Entre $R \$ 2.001,00$ e $R \$ 3.000,00$ mais de $\mathrm{R} \$ 3.000,00$

Resultado sobre Renda Familiar

Figura 3 -. Gráficos com alguns dos dados socioeconômicos obtidos a partir da aplicação dos questionários. 
compreendem e se relacionam com o patrimônio geológico ao seu redor.

Desta forma, para tentar compreender melhor como a população entrevistada entende o que é patrimônio (em sentido amplo), perguntou-se para os entrevistados o quê eles consideravam de tal forma importante, que merecia ser protegido e preservado para as futuras gerações também terem a oportunidade de conhecer. Para isso, foi apresentado ao entrevistado um conjunto de palavras. Quando a resposta era afirmativa, a palavra era assinalada. Se a pessoa não tinha certeza, mas afirmasse que dependia da situação, a palavra era marcada, porque ela já tinha associado o significado desse vocábulo ao patrimônio em alguma circunstância.

As palavras foram selecionadas buscando envolver o máximo de categorias patrimoniais possíveis: cultural e natural, tangível e intangível, de cunho histórico, artístico, científico, arquitetônico, entre outras. O conjunto foi formado com 27 palavras, nesta ordem: casa, osso, rua, doce, montanha, pedra, praia, artesanato, arma, fóssil, comida, homem, robô, jacaré, Planeta Terra, dança, pintura de arte, prédio antigo, flor, lenda / história, árvore, caneta, site, DNA, computador, ovelha e novela. Pode-se aferir que quanto mais itens são considerados como patrimônio, mais abrangente será a percepção patrimonial da população entrevistada.

Todo o conjunto de palavras obteve altos índices de representatividade e foram poucas as palavras com indicadores abaixo de $50 \%$. A palavra arma foi citada apenas $10 \%$ das vezes e as palavras novela $(28 \%)$, doce $(29 \%)$, robô $(32 \%)$, site $(38 \%)$, caneta $(40 \%)$, jacaré $(41 \%)$ e homem $(44 \%)$ foram as menos indicadas como patrimônio, atingindo menos da metade dos entrevistados, ou seja, não ultrapassando $50 \%$ das menções. No entanto, a maioria das palavras (19) foi interpretada como patrimônio por mais de $50 \%$ da população entrevistada. Destaca-se que o conceito fóssil (89\%) está entre os mais bem representados, junto com a palavra casa (89\%). A casa, interpretada como o patrimônio pessoal, também é sinônimo de lar, família e afeto. Mesmo em outras pesquisas, essa palavra foi a mais mencionada, indicando que ela é facilmente reconhecida como patrimônio seja no Sudeste ou no Nordeste (Souza, 2008).

As palavras que remetem ao patrimônio natural apresentaram uma boa colocação nas menções realizadas. Com exceção da palavra jacaré, todas as outras foram mencionadas por mais de $50 \%$ dos entrevistados. Vale a pena destacar que as palavras "pedra (77\%)", "montanha (78\%)", "Planeta Terra" (78\%), "árvore" (80\%) e "fóssil" (89\%) obtiveram média de $80 \%$, revelando que os elementos da natureza foram compreendidos como patrimônio de forma categórica, mesmo que "flor" (59\%); "ovelha" $(50 \%)$ e "praia" (68\%) não tenham atingido resultados tão altos. Esses elementos revelaram-se distantes da realidade dos entrevistados e isso pode ter contribuído para que esses resultados fossem mais baixos.

Os elementos relacionados ao patrimônio intangível e folclórico/popular foram pouco menos citados, mas ainda assim obtiveram bons índices, com destaque para as palavras "artesanato" (87\%); "lenda/história" (74\%); "rua" (69\%); "dança (63\%)" e "comida" (58\%). A média de citações dessas palavras foi de $70 \%$. Apenas a palavra "doce" obteve menos citações, com $29 \%$.

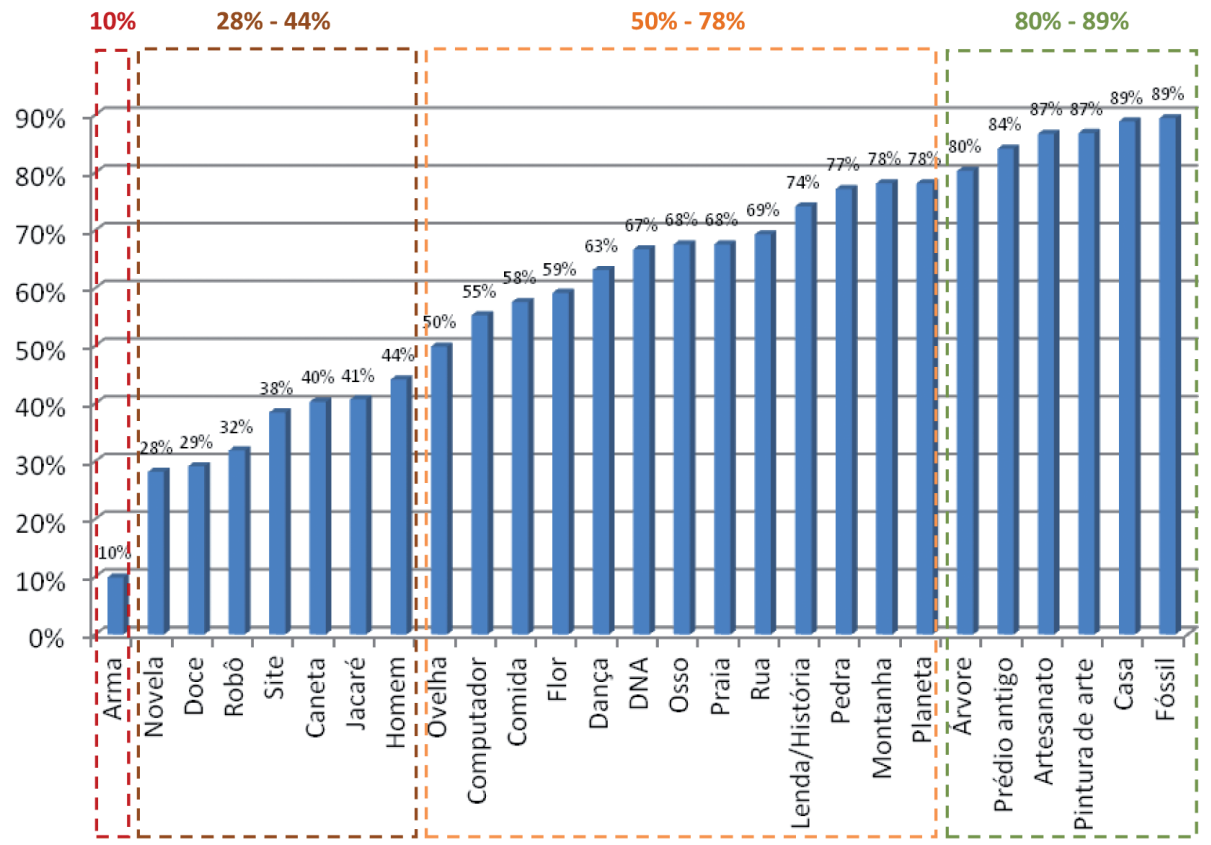

Figura 4. Gráfico ilustrativo do percentual quantitativo das palavras que foram interpretadas como patrimônio, em ordem crescente, da esquerda para direita. 
"Prédio antigo" (84\%) e "pintura de arte" (87\%), palavras que remetem à história e à arte, foram compreendidas como patrimônio com frequência, obtendo altos índices. As palavras que fazem referência à geodiversidade também apresentaram bons resultados "osso" (68\%); "pedra" (77\%); "montanha" (78\%); "Planeta Terra" (78\%) e "fóssil" (89\%). "Computador" (55\%), "DNA" (67\%), "robô" (32\%) e "site" (38\%), palavras utilizadas para verificar a percepção do patrimônio científico, não apresentaram índices altos.

É possível aferir que o discurso por detrás da atribuição de valor é o que é relevante para se compreender o que uma sociedade valoriza como patrimônio. Isso também se reflete também nos resultados apresentados. Quando um entrevistado assinalou uma palavra específica, uma relação de importância foi feita e ela reflete o que essa pessoa valoriza. Conhecer esses valores auxilia a compreender por que ocorrem alguns problemas de preservação e também auxilia na elaboração de estratégias para a mitigação de tais problemas.

Dependendo da associação que se fizesse, todas as palavras poderiam ser consideradas patrimônio, pois o valor de um patrimônio é atribuído por alguém, um ser humano, que faz alguma associação temporal, estética, científica ou outra. Um objeto corriqueiro do cotidiano, como uma caneta, sem (ou com pouco) valor econômico, não possui o mesmo valor de uma que pertenceu a alguma personalidade relevante. As canetas podem até ser fisicamente iguais, mas cada uma tem a sua história/memória, que lhe é atribuída, porque se trata de uma característica extrínseca e que necessita ser registrada para que o seu valor seja perpetuado. Essa é uma das funções da documentação museológica.

Embora essa seja uma questão subjetiva, é importante destacar que os entrevistados compreenderam o seu objetivo. Alguns termos de controle foram utilizados por serem, no imaginário popular, mais diretamente associados ao conceito de patrimônio, já que remetem aos conceitos históricos e artísticos. Como esperado, esses termos tiveram resultados altos (prédio antigo (84\%) e pintura de arte $(87 \%))$.

\section{Considerações finais}

Com a análise dos dados do diagnóstico de Santana do Cariri, no Geopark Araripe, foi possível conhecer ainda melhor como a população entrevistada se relaciona com a geodiversidade ao seu entorno e verificar se as estratégias já utilizadas na região estão funcionando, sejam elas de divulgação ou de conservação. Cada vez mais se deve buscar a aproximação da sociedade para que a geodiversidade seja consolidada como patrimônio e as pesquisas que enfocam a relação da população com tais elementos são uma boa alternativa.

O questionário é excelente instrumento de coleta de dados para pesquisas amostrais, pois fornece informações que não são encontradas em bibliografias e que possibilitam, além do enriquecimento da pesquisa, resultados únicos sobre o patrimônio geológico de uma região. O instrumento permite perceber as expressões, os valores e as apropriações dos indivíduos, incluindo a dicotomia entre o que se expressa de forma verbal com o que se expressa de forma corporal. O questionário no caso estudado foi muito útil como ferramenta de aproximação, o que incentiva mais trabalhos com tal abordagem em pesquisas sobre Patrimônio Geológico.

Os resultados encontrados na pesquisa sobre o tema "patrimônio" corroboram a teoria de que as palavras que remetem à História e à a Arte são mais frequentemente interpretadas e compreendidas como patrimônio. Isso demonstra que os entrevistados, além de compreenderem a pergunta, conseguiram fazer a associação dos elementos ao patrimônio. Mais que isso, os entrevistados fizeram comentários justificando as decisões com argumentos coerentes ao proferirem suas respostas. Pode-se aferir que, quanto mais itens são considerados como patrimônio, mais abrangente é a percepção patrimonial da população entrevistada. E esse foi o caso das pessoas participantes da pesquisa. Sua interpretação patrimonial foi considerada bastante abrangente pelos valores altos alcançados por todos os termos sugeridos.

Percebeu-se uma forte a associação com a natureza. Isso talvez tenha ocorrido porque as pessoas mais simples dão mais valor ao que está ao seu redor. Para quem possui poucas posses, o que tem, vale muito. $\mathrm{O}$ "patrimônio tangível" também foi bastante reconhecido, mas a maior parte dos elementos relacionados ao patrimônio intangível não atingiram os mesmos resultados, pois muitos não compreenderam como eles são preservados.

O "patrimônio científico", no sentido de tecnológico, talvez ainda represente uma realidade um pouco distante, pois foram pouco compreendidos como patrimônio. Isso talvez esteja relacionado ao fato desses itens estarem presentes no dia a dia e 
serem interpretados como algo comum, dificultando a valoração. Outra possibilidade está relacionada ao fato de tais elementos serem contemporâneos e não possuírem características temporais de antiguidade.

Os elementos relacionados à "geodiversidade" foram interpretados como patrimônio, demonstrando que as rochas e os fósseis estão presentes no imaginário social dos respondentes.

É possível concluir que o conceito patrimonial está fortemente relacionado à temporalidade para a comunidade estudada. Quanto mais antigo algo é, mais valor patrimonial lhe foi atribuído. O viés estético também está presente de forma recorrente nas associações e interpretações dos elementos como patrimônio. No entanto, os elementos mais corriqueiros, presentes no dia a dia, receberam pouco destaque em relação aos mais incomuns.

\section{Agradecimentos}

Os autores agradecem ao CNPq e FAPERJ pelo apoio na realização das pesquisas em Santana do Cariri, bem como à população do município que respondeu ao questionário. Este trabalho é parte da pesquisa relativa à Tese de Doutorado da primeira autora, realizado no PPGL - Programa de Pós-Graduação em Geologia da UFJ.

\section{Referências}

Aguiar V.R.L., Medeiros C.M. 2009. Entrevistas na pesquisa social: o relato de um grupo de foco nas licenciaturas. In: Congr. Nac. Educação, EDUCERE, 9. Curitiba, 2009. Anais... Curitiba PUCPR, p. 10.710-8.
Babbie E. 1999. Métodos de pesquisas de Survey. Trad. G. Cezarino. Belo Horizonte: Ed. UFMG. 1999,. 513p.

Castro, A. R. de S. F. de. 2014. O patrimônio geológico sob a perspectiva da população residente no município de Santana do Cariri, Ceará. Tese (Doutorado em Geologia) apresentado ao Programa de Pós-graduação em Geologia, Rio de Janeiro: Universidade . Federal do . Rio de Janeiro, Rio de Janeiro, xix, . 300f. (Tese Dout. Geol, PPG Geologia). Tese de doutorado

Gil A.C. 1995. Métodos e técnicas de pesquisa social. 4. ed. São Paulo: Atlas. 200p.

IBGE Instituto Brasileiro de Geografia e Estatística. Brasil 2010. Censo Demográfico 2010. URL: http:// censo2010.ibge.gov.br/. Acesso 06.2012.

Laville C., Dionne J. 1999. A construção do saber: manual de metodologia da pesquisa em ciências humanas. Belo Horizonte: Ed. UFMG. p.183186.

Souza A.R.de. 2008. Geoconservação e musealização: a aproximação entre duas visões de mundo, os múltiplos olhares para um patrimônio. Rio de Janeiro: Univ. Fed. Rio de Janeiro. 146f. (Dissert. Mestr. Museologia e Patrimônio, MAST).

Teixeira I.S.N., Machado D.M.C., Castro A.R.S.F.de, Farias L.F. 2012. Uma ferramenta para compreender a apropriação do Patrimônio Geológico pela sociedade: um estudo sobre o Morro do Corcovado/Rio de Janeiro. Anuário Inst. Geociências UFRJ, 35(1):123-132. DOI: 2012_1_123_132.

Viana M.S.S. 1996. Patrimônio Fossilifero. Recife: Depto. Geol., Univ. Fed. Pernambuco1996. 3 pp. (mat. didát. inédito, notas de aula),

Vieira A.C.M. 2009. O olhar da comunidade sobre o patrimônio: um estudo de caso no Parque Nacional da Tijuca. Rio de Janeiro: Univ. Fed. Rio de Janeiro. 96f. (Trab. Concl. Curso Bach. Museologia). , $96 f$

RESUMO : A aproximação com a sociedade é fundamental para consolidar a geodiversidade como patrimônio. Este trabalho objetiva apresentar como a população residente no município de Santana do Cariri, Ceará, parte do Geopark Araripe, percebe e se relaciona com a geodiversidade ao seu entorno. Foi elaborado um questionário e apresentados os resultados de sua aplicação a 700 moradores. Foi possível verificar que a população conhece e se relaciona com o meio geológico, mas de forma distinta da relação que a comunidade geocientífica o faz. A geodiversidade está presente nas ações cotidianas e faz parte da identidade local, numa dinâmica própria de relações sociais e patrimoniais. Pôde-se aferir que a percepção patrimonial dos entrevistados foi abrangente e que 0 conceito patrimonial está fortemente relacionado à temporalidade e ao viés estético. A geodiversidade está presente no imaginário social dos respondentes, uma vez que as rochas e os fósseis foram considerados como patrimônio.

Palavras-chave: Questionário; Pesquisa de Público; Patrimônio Geológico; Santana do Cariri, Ceará 